\title{
Diagnosis and natural history of Ebstein's anomaly
}

\author{
DOROTHY J RADFORD, R F GRAFF, G H NEILSON \\ From the Department of Cardiology, The Prince Charles Hospital, Brisbane, Queensland 4032, Australia
}

SUMMARY Thirty five cases of Ebstein's anomaly were diagnosed by cardiac catheter study or echocardiography between 1962 and 1984. The anomaly was an isolated abnormality in 27 patients; the remainder had additional heart lesions. Six patients have died and four of these had other cardiac lesions. Thirteen are currently symptom free. Twelve cases presented with cyanosis and heart murmur on the first day of life. Eight of these had associated thrill which is a rare finding in neonates. As pulmonary vascular resistance fell there was clinical improvement. This was assisted by oxygen treatment. Another two cases presented in the first week of life and 10 in the first decade with a murmur or supraventricular tachycardia. Eleven cases presented as adolescents or adults with a murmur, cardiomegaly, or cardiac symptoms. Three patients were seen initially in the sixth decade. Clinical diagnosis was correct in only one adult.

Twenty five patients had cardiac catheterisation. Important arrhythmias occurred in 10 cases, and two required cardioversion. Difficulty was experienced in entering the pulmonary artery in 11 infants and children. Diagnosis at initial catheter study was incorrect in four patients.. Echocardiograms were recorded in 29 cases. Earlier $M$ mode measurements of time delay of tricuspid closure compared with mitral closure did not always lead to the correct diagnosis. Cross sectional studies gave good images of tricuspid leaflet displacement, its tethering, and the atrialised portion of the right ventricle and have facilitated the diagnosis of more cases in recent years. Echocardiography is the procedure of choice for diagnosis of Ebstein's anomaly.

In 1866 Wilhelm Ebstein reported his necropsy findings in a cyanosed 19 year old labourer who had had dyspnoea and palpitation since childhood. ${ }^{2}$ The description of a congenital heart abnormality was illustrated by meticulous hand drawings which showed $(a)$ a severe malformation of the tricuspid valve; $(b)$ absence of the valve to the coronary sinus, and; $(c)$ a patent foramen ovale. Several similar cases were described over the next seventy years and the eponym Ebstein's disease was applied to them. ${ }^{34}$ It was not until 1949 that a case was diagnosed clinically. ${ }^{5}$

The basic anatomical abnormality consists of displacement of the septal and posterior leaflets of the tricuspid valve from the atrioventricular annulus into the body of the right ventricle. This results in atrialisation of a portion of the right ventricle. The

Requests for reprints to Dr DJ Radford, Department of Cardiology, The Prince Charles Hospital, Rode Road, Chermside, Brisbane 4032, Queensland, Australia.

Accepted for publication 22 July 1985 anterior leaflet is also abnormal and is usually large and sail-like. ${ }^{6}$

We have reviewed the diagnosis and natural history of Ebstein's anomaly in the light of currently available diagnostic techniques.

\section{Patients and methods}

All patients in whom Ebstein's anomaly was diagnosed by cardiac catheterisation or echocardiography or both at the Prince Charles Hospital between 1962 and 1984 are included. Hospital records, electrocardiograms, chest $x$ ray films, haemodynamic data from catheter studies, angiograms, and echocardiograms were reviewed.

\section{Results}

There were 35 cases of which 18 were female and 17 male. Simple Ebstein's anomaly was present in 27 patients and eight had other complicating cardiac lesions, most of which affected the right ventricular or tflow tract. Additional pulmonary valve stenosis 


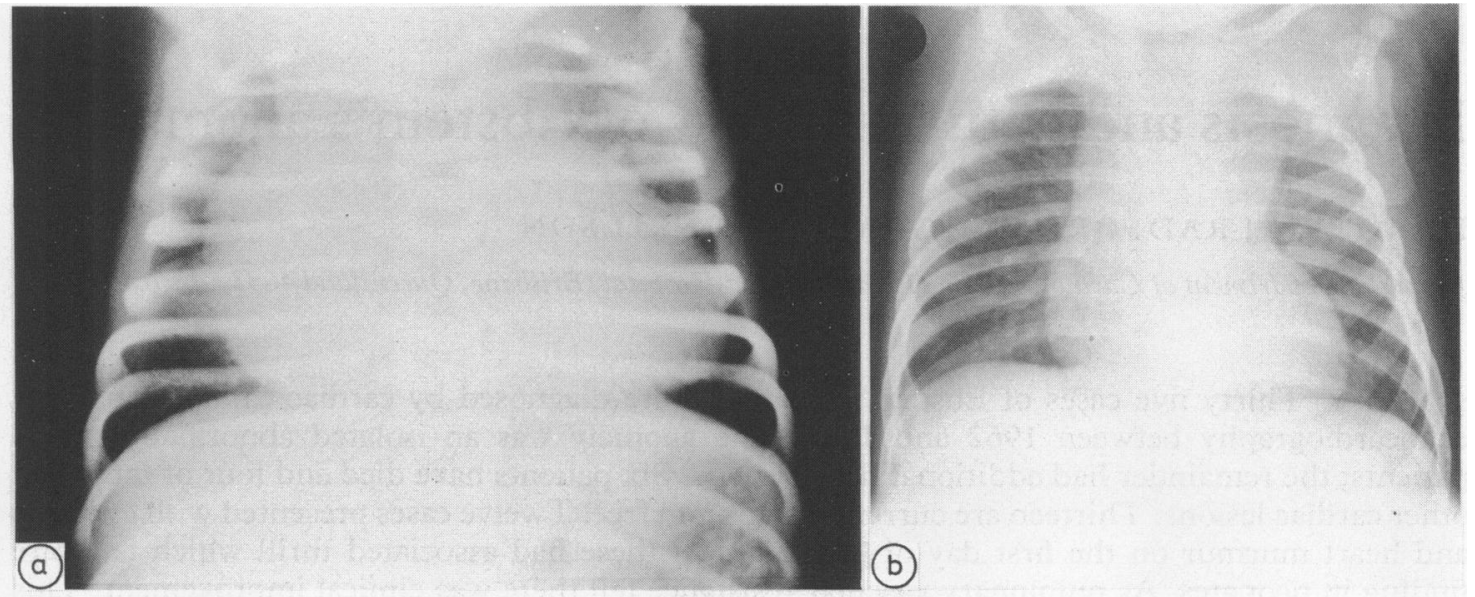

Fig. 1 Chest $x$ ray films of a baby with Ebstein's anomaly showing (a) massive cardiomegaly and oligaemic lung fields at 1 day and $(b)$ aged 5 months, showing that the size of the heart is considerably reduced and that the lung fields are normal.

was present in three, pulmonary atresia in two, a double outlet right ventricle with pulmonary stenosis in one, and two had corrected transposition of the great arteries with coarctation of the aorta.

\section{PRESENTATION}

Fourteen patients presented as neonates, 13 of them had cyanosis and a murmur and one had gross hydrops fetalis and supraventricular tachycardia (rate $>300$ beats per minute). Ten patients presented as infants and children, five with a murmur, three with supraventricular tachycardia, one with cyanosis, and one with widespread oedema.

Eleven patients did not present until they were adolescents or adults; three of them were over fifty. Palpitation, dyspnoea, and chest pain were the presenting features in seven, while two were found to have cardiomegaly on chest $x$ ray film and two younger patients aged 16 and 25 had asymptomatic murmurs.

\section{Neonates}

Of 14 neonates, 12 presented on the first day of life and all had both cyanosis and a murmur. Eleven had loud pansystolic murmurs at the left sternal edge indicative of tricuspid incompetence, and eight of these had an associated thrill, which is a rare finding in a neonate. The cyanosis and murmurs tended to decrease or disappear over subsequent days as the pulmonary vascular resistance fell. The electrocardiograms were not always diagnostic, although 11 of the 14 neonates had right atrial hypertrophy ( $P$ wave greater than $3 \mathrm{~mm}$ ). The $Q R S$ axis varied from $30^{\circ}$ to $240^{\circ}$. Five had right bundle branch block (QRS duration $\geqslant 0.06 \mathrm{~s}$ ), and three had first degree heart block ( $P R$ interval duration $\geqslant 0 \cdot 10 \mathrm{~s}$ ). The car diothoracic ratio on chest $x$ ray film ranged from 0.51 to 0.90 with a mean of 0.73 . The heart size as determined by $x$ ray film became smaller with age (Fig. 1a and b).

The mother of one neonate had taken lithium carbonate in pregnancy. Another had had rubella infection and, in addition to Ebstein's anomaly, her

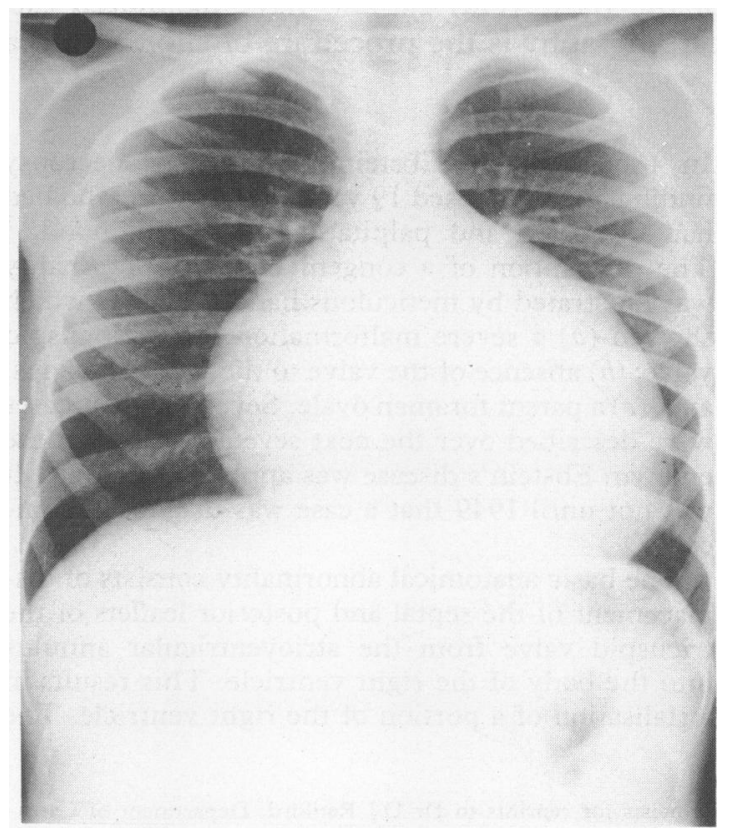

Fig. 2 Chest $x$ ray film of a 6 year old boy with Ebstein's anomaly showing the classic large rounded "clockface" heart. 


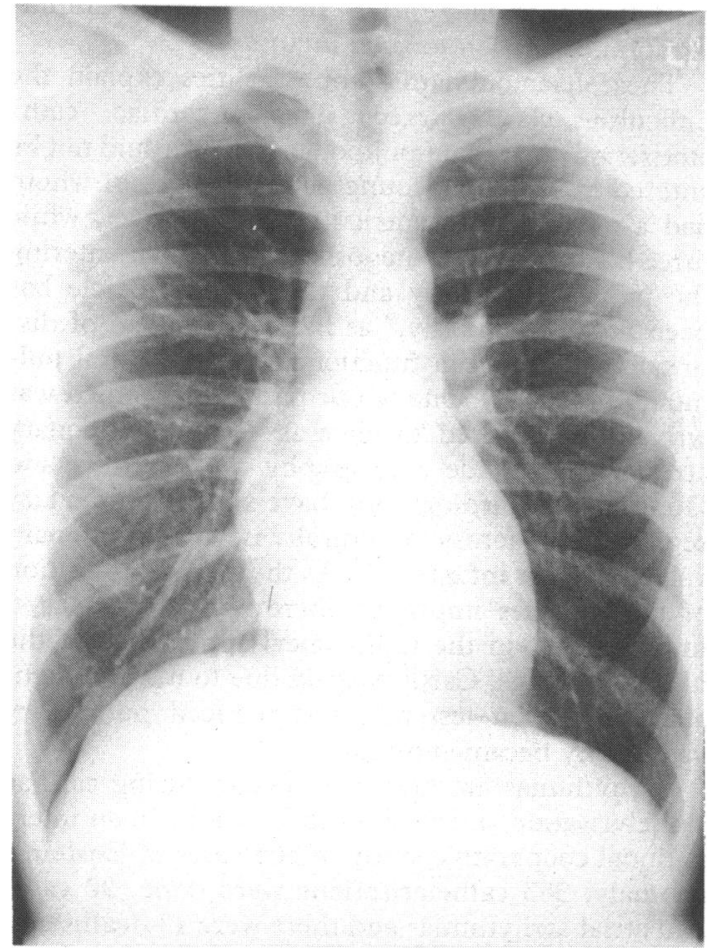

Fig. 3 Chest $x$ ray film of a 16 year old boy with Ebstein's anomaly. There is minor right atrial enlargement only.

infant had pulmonary stenosis, cataracts, and deafness.

\section{Children and adults}

The cardiothoracic ratio in patients who presented in infancy and childhood ranged from 0.4 to 0.7 (mean 0.57 ). In adults, it ranged from 0.46 to 0.67 (mean 0.55) (Figs. 2 and 3).

Most patients had either complete or incomplete right bundle branch block evident on the electrocardiogram. Two had evidence of accessory conducting pathways, three are now in atrial fibrillation, and one had complete heart block treated by pacemaker implantation.

Clinical findings in this group were variable and ranged from absent murmur with third or fourth heart sound, through soft mid-diastolic murmurs, to systolic murmurs of from grade 1 to grade 4 or 6 intensity. The anomaly was diagnosed on clinical evidence alone in only one adult.

\section{CARDIAC CATHETERISATION}

Catheter studies were done in 25 patients. There was important arrhythmia during the study in 12 patients and two required cardioversion. No deaths occurred as a result of catheterisation. In 11 infants and children the main pulmonary artery could not be entered; even floatation balloon catheters were not helpful. Three of these patients had associated pulmonary stenosis but the others had a patent right ventricular outflow tract. One such patient was wrongly considered to have pulmonary atresia. There was a right to left atrial shunt in 14. The initial catheter diagnosis was wrong in four patients and was later corrected by restudy in one and by echocardiography in three.

\section{ECHOCARDIOGRAPHY}

Echocardiograms were recorded in 29 patients and in 10 they were the only diagnostic investigation. Earlier $M$ mode studies to determine the delay of tricuspid valve closure on mitral closure were not always diagnostic. The delay ranged from 20 to 90 $\mathrm{ms}$ and should be $\geqslant 50 \mathrm{~ms}$ for diagnosis of Ebstein's anomaly. ${ }^{78}$ Cross sectional studies from the apical four chamber view were most helpful, particularly for measurement of septal leaflet displacement which is always $\geqslant 15 \mathrm{~mm}$ in patients with Ebstein's anomaly (Fig. 4). In the past three years 14 new cases of Ebstein's anomaly have been diagnosed by echocardiography. Other features noted on echocardiography were tethering of the septal leaflet of the tricuspid valve, exaggerated sail-like motion of the anterior leaflet, and the sizes of the atrialised portion of the right ventricle and of the functional right ventricle.

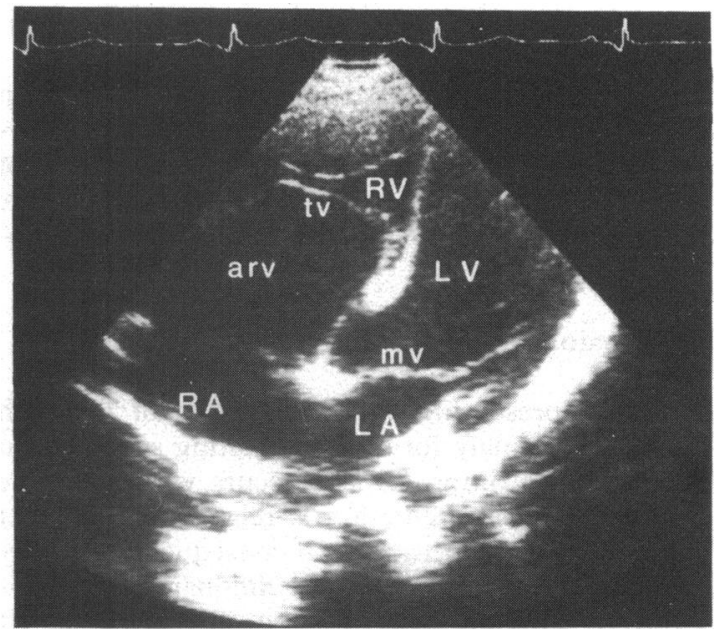

Fig. 4 Cross sectional echocardiogram in the four chamber apical view of a 7 year old boy with Ebstein's anomaly. The tricuspid valve (tv) is displaced $25 \mathrm{~mm}$ into the body of the right ventricle $(R V)$ as compared with the mitral valve (mv). This produces a small functional $R V$ and an atrialised portion of right ventricle (arv). The left atrium $(L A)$ and left ventricle ( $L V)$ are normal. 
FOLLOW UP

Six $(17 \%)$ of the 35 patients have died. Four deaths occurred in patients with associated abnormalities. Two died of supraventricular tachycardia-a 2 week old boy with a double outlet right ventricle and a girl aged 3 months with pulmonary atresia. Two patients died of infections-one aged 3 months with pulmonary atresia and viral pneumonia and one aged 2 years with pulmonary stenosis, a hypoplastic right ventricle, and pneumococcal septicaemia. One neonate who was wrongly thought to have associated pulmonary atresia died and there was one postoperative death after attempted tricuspid valve replacement and atrial septal defect closure in a 3 year old child.

Only two of our patients have had definitive surgery and one of them died (see above). The other had a closure of an atrial septal defect, pulmonary valvotomy, and tricuspid valve repair and a later tricuspid replacement. Operation in another six patients included one pulmonary valvotomy, one aortopulmonary shunt, two coarctation repairs, one division of a Kent bundle for Wolff-Parkinson-White syndrome, and one pacemaker insertion for complete heart block

Thirteen patients are currently symptom free, including seven who presented with cyanosis as neonates. Another 12 patients have had slight symptoms such as palpitation or mild dyspnoea. Four have had more serious problems including two with arrhythmias and systemic embolism, one with severe arrhythmias necessitating Kent bundle division, and one who is currently cyanosed and has limited exercise tolerance.

Six women with Ebstein's anomaly have been pregnant; they have a total of 12 children. No deterioration in cardiac function was noted as a result of pregnancy. Eight of the pregnancies occurred before the diagnosis of the cardiac lesion had been established.

\section{Discussion}

Neonates presenting on the first day of life with Ebstein's anomaly form an interesting subgroup in which clinical improvement occurs with age. The initial striking presentation is related to persistent pulmonary hypertension with consequent poor forward blood flow through the pulmonary valve, pronounced tricuspid regurgitation, and right to left shunting through the foramen ovale. These result in appreciable cyanosis and loud tricuspid regurgitant murmurs associated with a thrill. As pulmonary vascular resistance falls, forward blood flow improves, and cyanosis and murmur intensity decline as regurgitation becomes less. We have endeavoured to assist the fall of pulmonary artery pressure by the administration of oxygen to such infants.

These haemodynamic abnormalities explain the difficulties encountered during cardiac catheterisation. The main pulmonary artery could not be entered in 11 of our young patients, eight of whom had a patent right ventricular outflow tract, while three had pulmonary stenosis. Difficulty in entering the pulmonary artery and the right ventricle has been noted previously, ${ }^{9}$ as has the problem of distinguishing between functional and structural pulmonary atresia. ${ }^{10}$ One of our patients who died was wrongly considered to have associated pulmonary atresia. Retrograde aortography and contrast and Doppler echocardiography have shown pulmonary regurgitation across structurally normal pulmonary valves in such infants. ${ }^{1011}$ As the clinical condition of these babies improved there was an associated improvement in the radiological appearance of the heart and lungs. Cardiomegaly due to massive right atrial dilatation lessened and reduced pulmonary vascularity became normal.

Arrhythmias are known to occur during cardiac catheterisation and may result in death. In an international cooperative study of 505 cases of Ebstein's anomaly, 363 catheterisations were done, 90 cases had atrial arrhythmias and there were 13 deaths and six cardiac arrests. ${ }^{12}$ Wood stated that when the clinical diagnosis of Ebstein's anomaly is well founded, catheter study is contraindicated because of the risk of death from arrhythmia. ${ }^{13}$ Because cross sectional echocardiography now provides a reliable assessment of anatomy and function, invasive investigation of these patients is no longer necessary.

Echocardiography also led to the correct diagnosis in patients in whom the clinical features were not pathognomonic, and we have used this technique to diagnose 14 new cases in the past three years. In addition four wrong diagnoses based on catheter studies were corrected. The apical four chamber view is the best for cross sectional echocardiographic diagnosis. This allows the atrioventricular ring to be imaged simultaneously with the displaced tricuspid valve leaflets and demonstrates the size of the atrialised portion of the right ventricle. ${ }^{14}$ Since the tricuspid valve is normally slightly displaced apically in comparison with the mitral valve, diagnostic criteria are necessary to distinguish the displacement caused by Ebstein's anomaly. From anatomical and echocardiographic studies, a displacement of $15 \mathrm{~mm}$ in children and $20 \mathrm{~mm}$ in adults has been found to be discriminatory. ${ }^{15}$ Another study related the displacement distance of the septal leaflet of the tricuspid valve to the body surface area and showed that a displacement index of $\geqslant 8 \mathrm{~mm} / \mathrm{m}^{2}$ was a sensi- 
tive indicator of Ebstein's anomaly. ${ }^{16}$ Apart from its usefulness in primary diagnosis, cross sectional echocardiography was valuable in assessing patients for operation and deciding preoperatively which patients required plastic repair for plication of the atrialised right ventricle and tricuspid annuloplasty rather than tricuspid valve replacement. ${ }^{17}$

Possible prognostic factors in Ebstein's anomaly have been assessed in several studies and those features associated with poor outcome were: $(a)$ other complicating cardiac lesions; (b) persistent cyanosis as a result of right to left atrial shunting; $(c)$ diagnosis made in infancy; $(d)$ severe cardiomegaly; $(e)$ development of dyspnoea at rest; and $(f)$ right heart failure. 891819

Our experience confirms that the outcome is poor in patients with associated cardiac lesions. Four of six deaths in our series were in this category. We do not, however, agree that diagnosis in infancy is a prognostic factor in itself. The condition of neonates usually improved when they had simple Ebstein's anomaly and seven are currently symptom free. Although five of 14 patients presenting as neonates have subsequently died, only one had an uncomplicated lesion. In one case an incorrect diagnosis of pulmonary atresia was made, and because a duct dependent situation was assumed, oxygen treatment was not given. Thus no assistance was given to reduce pulmonary hypertension.

Since operation for Ebstein's anomaly has been associated with a high mortality rate, ${ }^{12}$ operation has not been recommended unless patients have severe symptoms. Recent surgical results are better ${ }^{20}$ but there is still no indication to recommend early surgery when it is evident that many patients with this anomaly remain symptom free or have only mild symptoms for years.

An association between the use of lithium carbonate during pregnancy and Ebstein's anomaly has been reported. ${ }^{21}$ The mother of one of our infants had taken lithium. An association between maternal rubella and Ebstein's malformation has also been reported. ${ }^{22}$

Our series of six women with Ebstein's anomaly who had 12 pregnancies is large in comparison with the case reports ${ }^{2324}$ and small series ${ }^{25}$ previously reported. Our experience confirms previous conclusions that women who are not cyanosed and have mild Ebstein's anomaly may successfully and safely complete a normal pregnancy.

\section{References}

1 Ebstein W. Ueber einen sehr seltenen Fall von Insufficienz der Valvula tricuspidalis, bedingt durch eine angeborene hochgradige Missbildung derselben. Archiv fur Anatomie, Physiologie und wissenschaftliche medicin 1866; 33: 238-54.

2 Schiebler GL, Gravenstein JS, Van Mierop LHS. Ebstein's anomaly of the tricuspid valve: translation of original description with comments. Am $\mathcal{f}$ Cardiol 1968; 22: 867-73.

3 Yater WM, Shapiro MJ. Congenital displacement of the tricuspid valve (Ebstein's disease): review and report of a case with electrocardiographic abnormalities and detailed histologic study of the conduction system. Ann Intern Med 1937; 11: 1043-62.

4 Mann RJ, Lie JT. The life story of Wilhelm Ebstein (1836-1912) and his almost overlooked description of a congenital heart disease. Mayo Clin Proc 1979; 54: 197-204.

5 Tourniaire A, Deyrieux F, Tartulier M. Maladie d'Ebstein: essai de diagnostic clinique. Arch Mal Coeur 1949; 42: 1211-6.

6 Anderson KR, Zuberbuhler JR, Anderson RH, Becker AE, Lie JT. Morphologic spectrum of Ebstein's anomaly of the heart. A review. Mayo Clin Proc 1979; 54: 174-80.

7 Daniel W, Rathsack P, Walpurger G, et al. Value of $M$-mode echocardiography for non-invasive diagnosis of Ebstein's anomaly. Br Heart $\mathcal{F} 1980$; 43: 38-44.

8 Giuliani ER, Fuster V, Brandenburg RO, Mair DD. Ebstein's anomaly: the clinical features and natural history of Ebstein's anomaly of the tricuspid valve. Mayo Clin Proc 1979; 54: 163-73.

9 Kumar AE, Fyler DC, Miettinen O, Nadas AS. Ebstein's anomaly. Clinical profile and natural history. Am F Cardiol 1971; 28: 84-95.

10 Freedom RM, Culham G, Moes F, Olley PM, Rowe RD. Differentiation of functional and structural pulmonary atresia: role of aortography. Am $\mathcal{F}$ Cardiol 1978; 41: 914-20.

11 Smallhorn JF, Izukawa T, Benson L, Freedom RM. Non-invasive recognition of functional pulmonary atresia by echocardiography. Am $\mathcal{F}$ Cardiol 1984; 54: 925-6.

12 Watson $\mathrm{H}$. Natural history of Ebstein's anomaly of tricuspid valve in childhood and adolescence. An international co-operative study of 505 cases. Br Heart $\mathcal{f}$ 1974; 36: 417-27.

13 Wood P. Diseases of the heart and circulation. 3rd ed. London: Eyre and Spottiswoode, 1969: 415.

14 Ports TA, Silverman NH, Schiller NB. Twodimensional echocardiographic assessment of Ebstein's anomaly. Circulation 1978; 58: 336-43.

15 Gussenhoven EJ, Stewart PA, Becker AE, et al. "Offsetting" of the septal tricuspid leaflet in normal hearts and in hearts with Ebstein's anomaly. Am $\mathcal{F}$ Cardiol 1984; 54: 172-6.

16 Shiina A, Seward JB, Edwards WD, Hagler DJ, Tajik AJ. Two-dimensional echocardiographic spectrum of Ebstein's anomaly: detailed anatomic assessment. F $\mathrm{Am}$ Coll Cardiol 1984; 3: 356-70.

17 Shiina A, Seward JB, Tajik AJ, Hagler DJ, Danielson GK. Two-dimensional echocardiographic-surgical correlation in Ebstein's anomaly: pre-operative determination of patients requiring tricuspid valve plication vs replacement. Circulation 1983; 68: 534-44.

18 Hansen JF, Leth A, Dorph S, Wennevold A. The 
prognosis in Ebstein's disease of the heart. Long term follow-up of 22 patients. Acta Med Scand 1977; 201: 331-5.

19 Simcha A, Bonham-Carter RE. Ebstein's anomaly. Clinical study of 32 patients in childhood. Br Heart $\mathcal{F}$ 1971; 33: 46-9.

20 Danielson GK, Fuster V. Surgical repair of Ebstein's anomaly. Ann Surg 1982; 196: 499-503.

21 Park JM, Sridaromont S, Ledbetter EO, Terry WM. Ebstein's anomaly of the tricuspid valve associated with prenatal exposure to lithium carbonate. $A m \mathcal{F}$ Dis Child 1980; 134: 703-4.
22 Bialostozky D, Horwitz S, Espino-Vela J. Ebstein's malformation of the tricuspid valve. A review of 65 cases. Am f Cardiol 1972; 29: 826-36.

23 Waickman LA, Skorton DJ, Varner MW, Ehmke DA, Goplerud CP. Ebstein's anomaly and pregnancy. $A m \mathcal{F}$ Cardiol 1984; 53: 357-8.

24 Littler WA. Successful pregnancy in a patient with Ebstein's anomaly. Br Heart $\mathcal{f}$ 1970; 32: 711-3.

25 Whittemore R, Hobbins JC, Engle MA. Pregnancy and its outcome in women with and without surgical treatment of congenital heart disease. Am $\mathcal{F}$ Cardiol 1982; 50: $641-51$. 